\title{
Organ donation and kidney sales
}

\author{
Mohamed A Ghoneim
}

Kidney transplantation is considered the treatment modality of choice for the majority of patients with end-stage renal disease; however, the shortage of suitable organs represents a bottle-neck restricting its potential. In developing countries, with a background of poverty and polarization of wealth, commercial living-unrelated donation has inevitably emerged. Illiterate and poor individuals, undocumented immigrants, prisoners and refugees are now a major source of organs for the rich patient tourists who can afford to pay for transplant kidneys. For example, it has been reported that of the 2,000 kidney transplantations performed in Pakistan in 2005, as many as two-thirds involved foreign recipients (Shimazono Y [2007] Bull World Health Organ 12: 955-962).

This trade in kidneys has raised profound questions of justice and human rights in the health-care domain. Guidelines produced by the World Health Organization in 1991 state that "the human body and its parts cannot be the subject of commercial transactions". Some authorities working in the field have, however, expressed a different opinion, stating that the realities of life in developing countries have not been properly considered or understood (Radcliffe-Richards J et al. [1998] Lancet 352: 1950-1952). Such authors argue that, although the most common objection to kidney selling is exploitation of the poor, the vendors themselves are anxious to sell in order to extricate themselves from poverty and debt. In addition, and as a result of prohibition of commercial donation, transplantation might be carried out secretively under less than optimum conditions with uncertain and undocumented results. Furthermore, donors might be underpaid, cheated, or waste the money they receive.
... although the

most common

objection to

kidney selling

is exploitation

of the poor,

the vendors

themselves

are anxious

to sell....

MA Ghoneim is Professor of Urology at the Urology and Nephrology Center, Mansoura, Egypt.

\section{Competing interests}

The author declared no

competing interests.

www.nature.com/clinicalpractice doi:10.1038/ncpuro1205
Persuasive arguments maintain that the best way to address these problems, while accepting the realities of life, would be by regulation of organ selling, and perhaps by creation of a central purchasing system to provide screening, counseling, reliable payment, insurance and financial advice. These ideas have been adopted in Iran in a system known as the 'Iranian Model', a governmentcontrolled program for non-directed livingunrelated paid donation first conceived in 1988 . The central body of this system is the Dialysis And Transplant Patients Association (DATPA; an Iranian nonprofit organization run by volunteers). One of the main functions of this association is to locate and distribute kidneys from living-unrelated donors. No broker or agency has a role in the process, and all procedures are carried out for free in University Hospitals. After surgery, the donor receives an award and lifelong health insurance from the government, in addition to an agreed compensation. In this manner, there is no commercialism, no financial benefits for the transplant team, and rich and poor receive the same standard of treatment. As a result of implementing this system, the number of transplantations performed in Iran increased substantially, and the waiting lists were completely eliminated (Ghods AJ and Savai S [2006] Clin J Am Soc Nephrol 1: 1135-1145).

Fighting poverty and improving the socioeconomic status in developing countries will ultimately provide the solution to the problem of commercial organ donation. Selling organs on the black market will then no longer be an attractive option. In the meantime, centralized purchasing systems might offer a way of lessening the exploitation of the world's poorest and most vulnerable individuals. 